\title{
Robert d'Orbigny, Le conte de Floire et Blanchefleur
}

\section{Maria Colombo Timelli}

\section{(2) OpenEdition}

\section{Journals}

\section{Édition électronique}

URL : https://journals.openedition.org/studifrancesi/40273

DOI : 10.4000/studifrancesi.40273

ISSN : 2427-5856

\section{Éditeur}

Rosenberg \& Sellier

\section{Édition imprimée}

Date de publication : 1 juillet 2004

Pagination : 156

ISSN : 0039-2944

\section{Référence électronique}

Maria Colombo Timelli, « Robert d'Orbigny, Le conte de Floire et Blanchefleur », Studi Francesi [En ligne], 142 (XLVIII | I) | 2004, mis en ligne le 30 novembre 2015, consulté le 09 septembre 2021. URL : http:// journals.openedition.org/studifrancesi/40273; DOI : https://doi.org/10.4000/studifrancesi.40273

\section{Ce document a été généré automatiquement le 9 septembre 2021.}

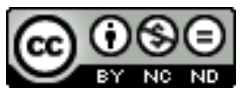

Studi Francesi è distribuita con Licenza Creative Commons Attribuzione - Non commerciale - Non opere derivate 4.0 Internazionale. 


\title{
Robert d'Orbigny, Le conte de Floire et Blanchefleur
}

\author{
Maria Colombo Timelli
}

\section{RÉFÉRENCE}

ROBERT D'ORBIGNY, Le conte de Floire et Blanchefleur, publié, traduit, présenté et annoté par Jean-Luc Leclanche, Paris, Champion, 2003, («Champion Classiques Moyen Age», 2), pp. 221.

Conservé dans trois manuscrits complets et dans un important fragment anglonormand, le Conte a fait l'objet de quelques éditions modernes, dont celle procurée par le même Jean-Luc Leclanche en 1980 pour les CFMA (n. 105). Celle qu'il présente dans cette nouvelle collection Champion, toujours fondée sur le manuscrit A (Paris, BnF fr. 375), sans conteste le meilleur de la tradition, est accompagnée d'une traduction en français moderne en prose. L'Introduction (pp. I-XXIX) rend d'abord rapidement compte de la transmission médiévale du texte et des aspects linguistiques (de l'auteur et du scribe) du manuscrit de base, marqué de traits picardisants malgré la provenance tourangienne de l'auteur; elle propose ensuite quelques remarques intéressantes sur les sources possibles et sur des éléments d'intertextualité, qui permettent de situer la composition du texte vers 1150 . L'étude du style et de la versification, bien que nécessairement synthétique, met en relief quelques caractéristiques significatives de l'écriture poétique de Robert d'Orbigny: la pratique de l'enjambement à l'intérieur du couplet d'octosyllabes, de nombreuses interventions d'auteur, l'insertion de quelques pauses lyriques (sans modification métrique), et de certains morceaux «obligés» dans la littérature narrative du XII ${ }^{e}$ siècle: descriptions et portaits notamment, dans lesquels l'auteur donne la mesure de sa maîtrise de la rhétorique. Le Conte a joui d'un succès certain, dont témoignent une traduction norroise dès 1220 , deux réfections en flamand (XIII ${ }^{\mathrm{s}}$.) et en allemand (début du XIII ${ }^{\mathrm{e}} \mathrm{s}$.), des réécritures en prose et de nombreuses mentions jusqu'au début du XIV ${ }^{\text {fe }}$ siècle. 
2 Le texte est bien édité, la traduction agréable et précise, les notes en bas de page rendent compte de certains problèmes concernant aussi bien le texte original que la traduction elle-même. Les annexes contiennent les compléments à l'édition: leçons rejetées du ms. A (appendice I, pp. 177-183), texte et traduction de deux développements propres de A (appendice II, pp. 185-199), table des noms propres (pp. 201-209). Le Glossaire, imprévu dans une édition bilingue, est nécessairement très sélectif (pp. 211-221).

3 Les fautes d'impression sont rares, et semblent relever, plutôt que de la négligence, d'une certaine hâte dans la composition du volume: à la p. XXIX de l'Introduction, le renvoi aux pages de la Bibliographie a sauté, le v. 1403 est sans doute incomplet du numéral «IV», que l'on peut déduire cependant de la traduction en regard; quelques imprécisions dans la mise en page ne dérangent au fond pas la lecture. 